\title{
Analysis of Extraction and Transesterification Conditions for Phaeodactylum Tricornutum Microalgae
}

\author{
J.L. Salgueiro ${ }^{1}$, Ángeles Cancela ${ }^{1}$, Ángel Sánchez ${ }^{1}$, Rocío Maceiras ${ }^{2}$, Leticia Pérez ${ }^{1}$
}

\begin{abstract}
An increasing global demand for a biologically produced energy source has emerged due to the exhausted usage of non-renewable petroleum-derived fuels. Microalgae are a promising feedstock for biofuels because of their capability to produce lipids. In this paper, two operations for biodiesel production were studied from Phaeodactylum Tricornutum microalgae. This marine diatom shows a big potential to produce biodiesel due to its fast growth and lipid accumulation ability. In this research, first the microalgae was harvesting using an inorganic flocculant as copper (II) sulphate (CuSO4). When the dose was $200 \mathrm{mg} / \mathrm{L}$, the microalgae recovery was close $83 \%$ in the first five minutes. After that, the microalgal oil was separated by ultrasound extraction process, using ethanol as solvent. This allows to analyze the oil content of the microalgae which is used later in the transesterification. The obtained lipid content was 38\% wt. Temperature variations were observed in this process. Finally, a direct transesterification reaction took place with base catalysis by three ways: traditional, microwave assisted and ultrasound assisted. Direct transesterification microwave assisted achieved $52 \%$ conversion to biodiesel versus $16 \%$ for the traditional method. However, the best performance $(90 \%)$ was obtained for ultrasound assisted transesterification.
\end{abstract}

Keywords: microalgae; harvesting; transesterification: microwave; ultrasound; extraction.

\section{Introduction}

Energy is highly indispensable to our day to day activities and it is required in all sectors of the economy including industry, agriculture and transportation among others for sustainable economic growth and development. The requirement is on a high increase due to rapid industrialization and huge numbers of vehicles (Agarwal, 2007). The increment of energy consumption and constant increase in the cost of energy has forced to look for alternative and renewable sources. Microalgae are considered promising candidates for fuel production because of their high photosynthetic efficiency, high growth rate, and high area-specific yield. The cultivation conditions of these organisms can be manipulated to induce the production of proteins, fatty-acids, vitamin A, minerals, pigments and other bio-compounds and their biomass can be used as a dietary supplement for humans and animals, including for aquaculture (Ono \& Cuello, 2004). The commercial production of microalgae derived biodiesel is still in the research and developmental stages, mainly due to the current prohibitive high costs associated with the biomass production and fuel conversion process. Schemes such as improving the biomass productivities, photo-bioreactor optimization and research into alternative microalgae-biodiesel conversion technologies have been increasingly investigated. This paper looks further at the extraction and transesterification conditions for the purpose of improving the method. 


\section{Materials and Methods}

\subsection{Strain and growth conditions}

Local strains of the microalgae Phaeodactylum Tricornutum was cultured in a $45 \mathrm{~L}$ photobioreactor of polyethylene under artificial illumination with 14/10 of light/dark cycle. Biomass was cultivated on medium which it consists the mixture of two different macronutrients solutions. One containing $\mathrm{NaNO}_{3}, \mathrm{KH}_{2} \mathrm{PO}_{4}, \mathrm{MgSO}_{4} \cdot 7 \mathrm{H}_{2} \mathrm{O}$ and $\mathrm{Na}_{2} \mathrm{CO}_{3}$, and the other $\mathrm{MgCl}_{2}$ $6 \mathrm{H}_{2} \mathrm{O}, \mathrm{CaCl}_{2} 2 \mathrm{H}_{2} \mathrm{O}, \mathrm{H}_{3} \mathrm{BO}_{3}, \mathrm{MnCl}_{2} 4 \mathrm{H}_{2} \mathrm{O}, \mathrm{ZnCl}_{2}, \mathrm{FeCl}_{3} 6 \mathrm{H}_{2} \mathrm{O}, \mathrm{CoSO}_{4} 7 \mathrm{H}_{2} \mathrm{O}, \mathrm{Na}_{2} \mathrm{MoO}_{4} 2 \mathrm{H}_{2} \mathrm{O}$, $\mathrm{CuSO}_{4} 5 \mathrm{H}_{2} \mathrm{O}$ and $\mathrm{Na}_{2}$ EDTA $2 \mathrm{H}_{2} \mathrm{O}$. The measured concentration from the culture was 17.200 cells/microliter and the approximate $\mathrm{pH}$ of the microalgae cultures was 8.63.

On completion of 8 days of cultivation period, the microalgae culture was harvested. Algal biomass was stored at room temperature after harvesting. All experiments were performed with cells from a single harvest.

\subsection{Harvest method: Coagulation}

Microalgal harvesting currently involves mechanical, chemical, biological and, to a lesser extent, electrical based methods (Barros, Gonçalves, Simões, \& Pires, 2015). Most microalgal harvest and recovery techniques have been developed based on technologies that have been used in water purification industry (Kim, et al., 2013). Flocculation is an efficient method to separate biomass. During flocculation, single cells form larger aggregates, and they are separated from the medium by simple gravity sedimentation. In addition, effective mixing significantly affects the performance of a flocculation process. Flash mixing is necessary to facilitate the well distribution of the flocculant within the particles in as short a time as possible. It helps to obtain a uniform mixture of the flocculant and the suspended cells to maximize effective destabilization of colloidal particles in order to initiate flocculation. For slow mixing, microalgae culture is only moderately stirred in order to increase contact between flocculating particles and to facilitate the development of large flocs (Ndikubwimana, Zeng, Liu, Chang, \& Lu, 2014).

All the flocculation experiments were carried out in $10 \mathrm{~L}$ reactor using copper (II) sulphate $\left(\mathrm{CuSO}_{4}\right)$ solution. The flocculant was added in a unique dose of $200 \mathrm{mg} / \mathrm{L}$, followed by flash mixing at $200 \mathrm{rpm}$ for $1 \mathrm{~min}$, and then slow mixing at $50 \mathrm{rpm}$ for $3 \mathrm{~min}$. The microalgal suspensions were left to settle at room temperature without agitation. Subsequently, the sample supernatants were removed from half the height of the clarified layer and were used to measure the optical density at wavelength $680 \mathrm{~nm}$ with a digital spectrophotometer Spectro 22 (Labomed, USA).

\subsection{Ultrasound assisted extraction}

Ultrasound is a sound of a frequency higher than that the human ear can respond. Ultrasound use increases the conversion, improves the yield, changes the reaction pathway and initiates the reaction in many biological, chemical, and electrochemical systems. In organic synthesis, the use of ultrasound can reduce the number of synthesis steps, the reaction time and the reaction temperature (Vlada Veljkovic', Jelena Avramovic', \& Olivera Stamenkovic', 2012). Novel techniques with ability to disruptive (disrupt the cell walls to force-release the lipids) are essential for efficient algal oil extraction (Martinez-Guerra, Gude, Mondala, Holmes, \& Hernandez, 2014).

When ultrasound is applied in liquid, there are two main mechanisms that the cells or other structures may be altered: cavitation and acoustic streaming. Cavitation is the production of microbubbles because of the applied ultrasound (Suslick \& Flannigan, 2008). As the microbubbles continue to expand and contract, they eventually become unstable and implode violently, sending shock waves that disrupt surrounding materials such as cells. Acoustic streaming is the 
mechanism that facilitates the mixing of the solution (Khanal, Montalbo, Leeuwen, Srinivasan, \& Grewell, 2007).

In the experiment, crude dried Phaeodactylum Tricornutum $(1 \mathrm{~g})$ was mixed with ethanol $(50 \mathrm{~mL})$ in flasks at room temperature $\left(20^{\circ} \mathrm{C}\right)$ for lipid extraction using ultrasound bath (Model S $300 \mathrm{H}$ from Elmasonic) with irradiation frequency of $37 \mathrm{kHz}$. The mixture was conducted in the ultrasonic bath for 30 minutes. Throughout the process, a thermometer inserted in the flask measured the temperature. After lipid extraction, the ethanol phase that contains the extracted lipids was separated from the microalgae biomass by vacuum filtration, followed by the solvent evaporation. The biomass microalgae was dried to constant weight in an oven at a temperature of $60^{\circ} \mathrm{C}$.

\subsection{Transesterification reaction}

\subsubsection{In situ transesterification reaction}

In situ transesterification allowed minimizing the requirement of solvents by merging the two steps to a single step (Guldhe, Singh, Rawat, \& Bux, 2014). Direct transesterification process of microalgae for biodiesel production has been carried out by homogeneous catalysis. Homogeneous alkaline catalysis has been the most used route for biodiesel production because it catalyzes the reaction at low temperature and atmospheric pressure and also a high conversion yield can be achieved in a short time.

In this research, the catalyst $(\mathrm{NaOH})$ was dissolved in methanol by vigorous stirring in a small reactor. The microalgae was transferred into the flask, and then, the catalyst/alcohol mixture was added to the microalgae. The molar ratio of methanol and microalgae was 12:1 while the amount of $\mathrm{NaOH}$ catalyst was $2 \mathrm{wt} \%$ of methanol.

The final mixture was stirred at $150 \mathrm{rpm}$ at atmospheric pressure. The reaction was conducted in a $250 \mathrm{~mL}$ flask for 180 minutes with a heating orbital stirrer (Ovan Maxi MD OL30-ME). Throughout the process, the temperature was fixed at $60{ }^{\circ} \mathrm{C}$. After the reaction, the solid residue was removed and the resulting liquid was decanted. A successful transesterification reaction produced two liquid phases: biodiesel and crude glycerin. Crude glycerin, the heavier liquid, was collected at the bottom after several hours of settling. Biodiesel and residual traces of methanol were recovered. In order to remove traces of methanol, the mixture was again introduced into the incubator for 8 hours at a temperature of $70{ }^{\circ} \mathrm{C}$. End of this time, the biodiesel was recovered and its conversion was determined.

\subsubsection{Microwave assisted transesterification}

Microwave irradiation has been used in the past and it is a constructive method to extract oils from biomass, animal fats and vegetable feedstock and can be easily scaled-up (HC, AC, \& FX, 2011). Microwave irradiation is known to be more efficient; on the average the cost of microwave heating is two thirds less than that of conventional heating. Microwave technology has resulted in the development of rapid, safe and cost-effective method for biodiesel production and it does not require samples to be devoid of water. The application of radio frequency microwave energy offered a fast and easy route to this valuable biofuel with the advantages of enhancing the reaction rate ( $2 \mathrm{~min}$ instead of $2 \mathrm{~h}$ process reaction) and thus improved the separation (SA, AA, \& ST, 2010). Therefore, in this study microwave irradiation technique was used for biodiesel production directly. Microwave irradiation can be a suitable method to decrease the cost of biodiesel and also promote the commercialization of biodiesel (Wahidin, Idris, \& Shaleh, 2014).

The current work carried out the optimization of a one-stage method whereby the microalgae of Phaeodactylum Tricornutum was converted to biodiesel using direct transesterification by microwave. The experiments was carried out using a domestic microwave oven (Becken Easycook Digital 2) operating at $2.45 \mathrm{GHz}$ for 4 minutes, in a batch mode under atmospheric pressure. Thus, $5 \mathrm{~g}$ of 
microalgae were loaded into a round bottom flask and $60 \mathrm{ml}$ of methoxide were added. The output of the domestic microwave reactor was $800 \mathrm{~W}$. Its modification to accommodate a distillation column has been described elsewhere (Groisman \& Gedanken, 2008). This modification, passing a distillation column through the MW oven, is aimed at enhancing safe operation by preventing the liquid from splashing. After the reaction, the mixture was cooled to room temperature.

\subsubsection{Ultrasound assisted transesterification}

There is an imperative need to develop an efficient, economically functional and environmental friendly biodiesel production process better than traditional methods. Ultrasound assisted transesterification is among these alternatives and innovative biodiesel production processes. The use of ultrasound has been already shown to be very effective for intensification of biodiesel production processes.

The application of ultrasound to microalgae in water, also known as sonication, utilizes the process of cavitation to disrupt the cell wall. Cavitation involves nucleation, growth and transient impulsive collapse of tiny bubbles in the liquid driven by bulk pressure variation due to ultrasound wave. Cavitation provides the physical effects of micro-turbulence and velocity/pressure shockwaves. Micro-turbulence provides intense mixing, while shockwaves cause disruption of the cell walls (Ranjan, Patil, \& Moholkar, 2010). The immense local temperatures and pressures and the extraordinary heating and cooling rates generated by collapse of cavitation bubbles provide an unusual mechanism for generating high-energy chemistry. These effects can reduce the reaction time required to obtain biodiesel.

The transesterification reaction was carried out in Erlenmeyer $100 \mathrm{~mL}$ round-bottom flasks. For the experiment, $5 \mathrm{~g}$ of Phaeodactylum Tricornutum was reacted with $60 \mathrm{~mL}$ methoxide (methanol and $\mathrm{NaOH} 2 \mathrm{wt} \%)$. The reactions were performed using ultrasound bath Model $\mathrm{S} 300 \mathrm{H}$ from Elmasonic, with a total power of $800 \mathrm{~W}$ for one hour and an ultrasound frequency of $37 \mathrm{kHz}$. The solution temperature was maintained constant at $30^{\circ} \mathrm{C}$ for all experiments by circulating water through the bath. When the reaction was completed, the product was purified.

\section{Results and Discussion}

\subsection{Harvest method: Coagulation}

The efficiency of the process was analysed based on the microalgae concentration with the time. Figure 1 shows the obtained result for copper (II) sulphate during the sedimentation process.

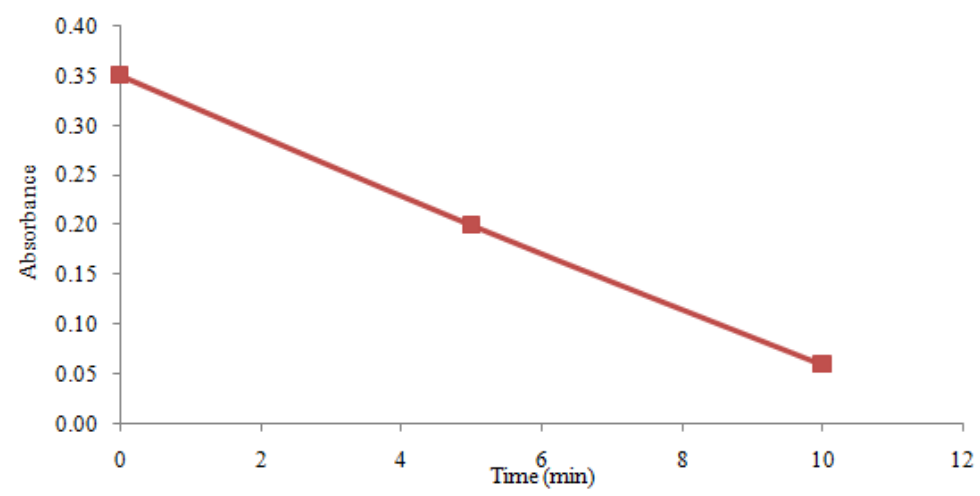

Figure 1. Absorbance of copper (II) sulphate. 
As shown in Figure 2, the use of copper (II) sulphate as a flocculant resulted in flocculation efficiencies of $83 \%$. The efficiency of the flocculation process was determined by the presence of microalgae at the bottom of the cylindrical beakers in terms of absorbance and its microalgae recovery was measured after 72 hours of sedimentation.

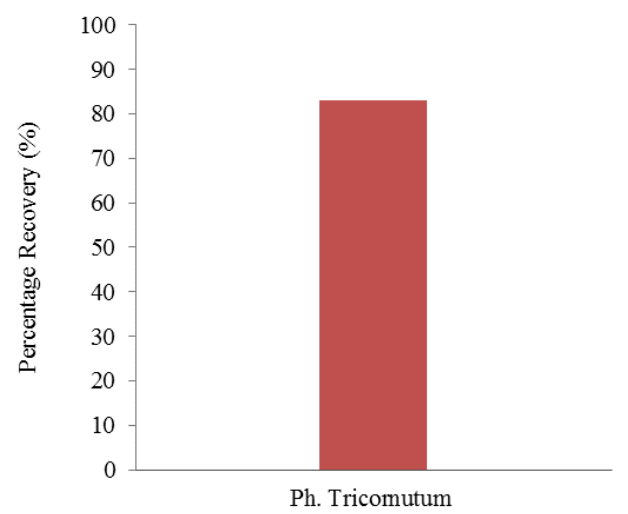

Figure 2. Microalgae recovery for the flocculation process.

This flocculation experiment illustrates that the flocculant dose of $200 \mathrm{mg} / \mathrm{L}$ was suitable to recovery the microalgae Selenastrum Tricornutum. From these results, it can be said that flocculation is an effective alternative for the processing of algae for biodiesel production.

\subsection{Ultrasound assisted Extraction}

The mechanical effects of ultrasonics, cavitation and streaming, are the predominant contributors to cell disruption to enhance lipid extraction. Throughout ultrasound-assisted extraction, the temperature was measured by a thermometer inserted in the flask. Thus, Figure 3 shows as the temperature increased with the time. This effect is due to the collapse of bubbles caused by cavitation produces intense local heating and high pressures, with very short lifetimes.

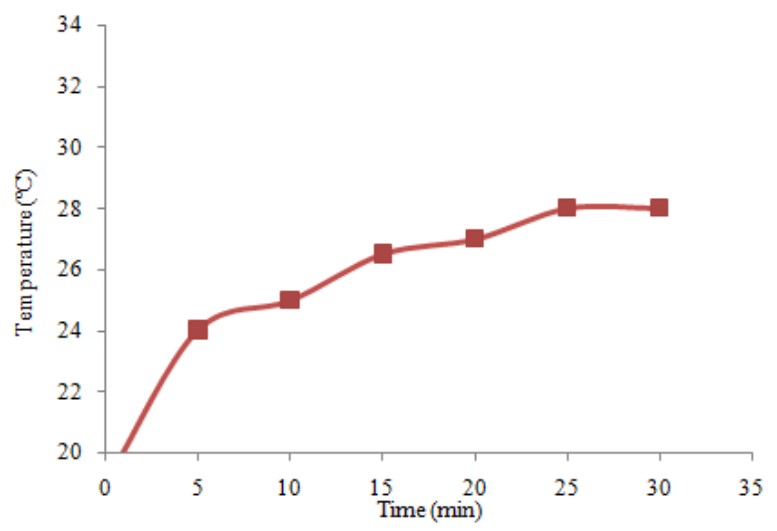

Figure 3. Microalgae recovery for the flocculation process.

Amount of $50 \mathrm{~mL}$ of ethanol as solvent in ultrasound assisted extraction achieved 38\% of extracted lipid. This extraction method should be performed in further researches with different amounts of solvents in order to obtain better results. 
Table 1. Percentage extracted lipids by Ultrasound.

\begin{tabular}{|c|c|c|}
\hline \multirow{2}{*}{ Method } & \multicolumn{2}{|c|}{ Amount of extracted lipids } \\
\cline { 2 - 3 } & Solvent & $\mathbf{\% ~ w / w}$ \\
\hline Ultrasound & Ethanol & 38.09 \\
\hline
\end{tabular}

\subsection{Transesterification reaction}

In this study, the use of non-conventional methods namely microwave and ultrasound for transesterification reaction of algal lipids using methanol as a solvent was investigated as well as in situ transesterification. In general, microwave and ultrasound possess the potentials to enhance the chemical reactions and extractive processes due to thermal and specific non-thermal effects associated with them.

In this study, the difference between the three methods is that in situ transesterification requires greater reaction time than microwave or ultrasound method obtaining worse biodiesel conversion. In the experiments, a same amount of methoxide was used. Ultrasound method achieved the highest conversion $(90 \%)$ in 60 minutes of reaction time. On the other hand, microwave method managed a $52 \%$ of biodesel conversion in a shorter time, only a few minutes after the beginning of the transesterification reaction $(4 \mathrm{~min})$ and finally, in situ transeterification achieved the worst yield. In situ transesterification needed 180 minutes to get only a $16 \%$ biodiesel conversion. Thus, it can be said that ultrasound and microwave methods were able to extract the lipids with lower solvent requirements. This can be due to microwave radiation and ultrasound accelerate the disruption of the microalgae cells, and as a result the release of oil is made easier.

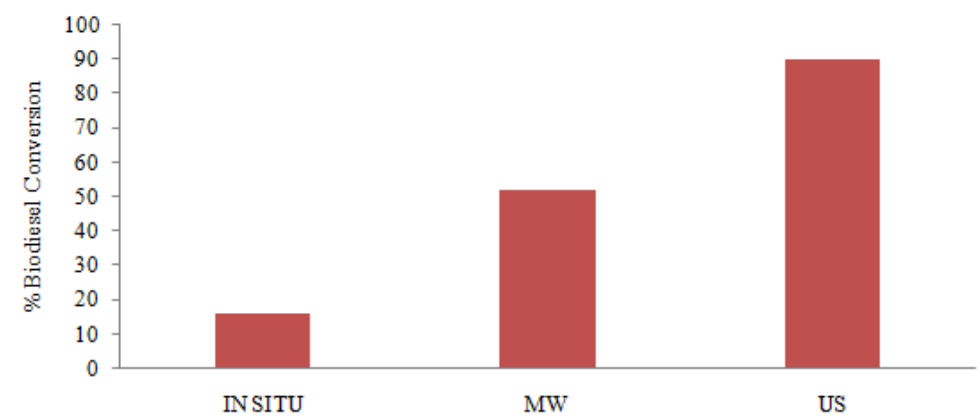

Figure 4. Biodiesel conversion by different technics of transesterification.

\section{Conclusions}

The obtained results of this study indicate that the microalgae Phaeodactylum Tricornutum could be a valuable candidate to be used for biodiesel production.

High percentage recovery was obtained with $200 \mathrm{mg} / \mathrm{L}$ of copper (II) sulphate, therefore $\mathrm{CuSO}_{4}$ is an effective inorganic flocculant. On the other hand, ultrasound assisted extraction technique achieved $38 \%$ of extracted lipids using ethanol as solvent.

Finally in this research, the effects of microwaves and ultrasound on transesterification of algal lipids from microalgae Phaeodactylum Tricornutum as well as in situ transesterification were studied. Based on obtained results, it can be concluded that the ultrasound seems to be the most simple and efficient method for one-stage direct transesterification ( $90 \%$ biodiesel conversion) due to its efficacy to destruction of the cells and accelerates better the transesterification reaction in a shorter reaction time. 


\section{References}

Agarwal, A. (2007). Biofuels (alcohols and biodiesel) applications as fuels for internal combustion engines. Progress in Energy and Combustion Science 33, 233-271.

Barros, I. A., Gonçalves, L. A., Simões, M., \& Pires, J. C. (2015). Harvesting techniques applied to microalgae: A review. Renewable and Sustainable Energy Reviews 41, 1489-1500.

Groisman, Y., \& Gedanken, A. (2008). Continuous flow, circulating microwave system and its application in nanoparticle fabrication and biodiesel synthesis. The Journal of Physical Chemistry C 112(24), 88028808.

Guldhe, A., Singh, B., Rawat, I., \& Bux, F. (2014). Synthesis of biodiesel by Scenedesmus sp. by microwave and ultrasound assisted in situ transesterification using tungstated zirconia as a solid acid catalyst. Chemical Engineering Research and Design Volume 92, 1503-1511.

HC, A., AC, G., \& FX, M. (2011). Advances and perspectives in using microalgae to produce biodiesel. Appl Energy 88, 3402-10.

Khanal, S., Montalbo, M., Leeuwen, J. V., Srinivasan, G., \& Grewell, D. (2007). Ultrasound enhanced glucose release from corn in ethanol plants. Biotecbnology and Bioengineering 98, 978-985.

Kim, J., Yoo, G., Lee, H., Lim, J., Kim, K., Kim, C. W., . . Y Yang, J.-W. (2013). Methods of downstream processing for the production of biodiesel from microalgae. Biotechnology Advances 31, 862-876.

Martinez-Guerra, E., Gude, V. G., Mondala, A., Holmes, W., \& Hernandez, R. (2014). Microwave and ultrasound enhanced extractive-transesterification of algal lipids. Applied Energy 129, 354-363.

Ndikubwimana, T., Zeng, X., Liu, Y., Chang, J.-S., \& Lu, Y. (2014). Harvesting of microalgae Desmodesmus sp. F51 by bioflocculation with bacterial bioflocculant. Algal Research Volume 6, Part B, 186-193.

Ono, E., \& Cuello, J. (2004). Design parameters of solar concentrating systems for CO2 mitigating algal photobioreactors. Energy 29, 1651-1657.

P., K., M., H., \& V., C. (2001). The electrodeless discharge lamp: a prospective tool for photochemistry Part. 3. The microwave photochemistry reactor. J. Photochem. Photobiol. A:Chem 140, 185-189.

Ranjan, A., Patil, C., \& Moholkar, V. (2010). Mechanistic assessment of microalgal lipid extraction. Ind Eng Chem Res 40, 2979-85.

SA, E. S., AA, R., \& ST, E. S. (2010). Production of biodiesel using microwave technique. Adv Res, 309-14.

Suslick, K. S., \& Flannigan, D. (2008). Inside a collapsing bubble: sonoluminescence and the conditions during cavitation. Annual Review of Physical Chemistry 59, 659-683.

Vlada Veljkovic', B., Jelena Avramovic', M., \& Olivera Stamenkovic', S. (2012). Biodiesel production by ultrasound-assisted transesterification: State of the arte and the perspectives. Renewable and Sustainable Energy Reviews 16, 1193-1209.

Wahidin, S., Idris, A., \& Shaleh, S. R. (2014). Rapid biodiesel production using wet microalgae via microwave irradiation. Energy Conversion and Management 84, 227-233. 
